Narratives of power and powerlessness: Cultural competence in social work with asylum seekers and refugees

Emmaleena Käkelä

School of Social Work and Social Policy, University of Strathclyde, Glasgow, UK

Emmaleena Käkelä emmaleena.kakela@ strath.ac.uk 


\title{
Narratives of power and powerlessness: Cultural competence in social work with asylum seekers and refugees
}

\author{
With increasing international migration, social workers have not only been \\ confronted with growing diversity, but also with the effects of displacement, \\ trauma and immigration controls in the lives of their service users. Although the \\ ongoing debates on migration, migrant integration and social cohesion have \\ facilitated a growing literature on, and demand for cultural competence in social \\ work, little progress has been made to arrive at an agreement of what exactly is \\ required from social workers in cross-cultural encounters. This paper draws from \\ the qualitative element of a mixed-methods study on social workers' experiences \\ of cross-cultural practice conducted in Glasgow, Scotland in 2016. By focusing \\ on social workers' experiences of accommodating and negotiating cultural \\ differences with asylum seekers, this paper illustrates how social workers are \\ moving beyond the cultural lens in understanding difference and disadvantage. \\ The findings suggest that whilst culture continues to influence social workers' \\ encounters with service users, addressing cultural conflicts requires social \\ workers to understand the complex power relations which asylum seekers are \\ subject to both within and beyond the care relationship. Practice perspectives on \\ the challenges and successes in cross-cultural social work illustrate the interplay \\ between cultural and structural considerations involved in social work with \\ asylum seekers.
}

Keywords: Cultural competence; social work practice; asylum seekers; diversity; structural inequality 


\section{Introduction}

Much like rest of Europe, Scotland has not been left untouched by the effects of increasing international migration. The number of people identifying as other than 'White Scottish' has doubled in just ten years, increasing in every local authority (Simpson, 2014). Glasgow, the biggest and most ethnically diverse city in Scotland, has continued to grow even more diverse due to the city's participation in the National Asylum Support Service dispersal scheme. At current, around 3000 asylum seekers continue to receive Section 95 support for housing and basic living expenses in Scotland, most of whom reside in Glasgow ${ }^{1}$ (Home Office, 2017). Whilst this does not directly translate to an increase in asylum seeking service users, the psychological and structural constraints faced by refugees mean that it is likely that social workers are increasingly witnessing the effects of global instabilities in the lives of their service users.

With increasing diversity, growing public and policy concerns over integration and social cohesion have coincided with renewed interest in cultural competence across the statutory care sector. Although there is a growing demand for social workers to attend to issues of diversity and difference, little is known in regard to how social workers themselves are experiencing the changes in their role and the society in which they operate. This article draws from a study which builds on the limited research on

${ }^{1}$ The UK Home Office does not release separate statistics for Scotland, making it difficult to accurately estimate the number of dispersed asylum seekers; Section 95 support excludes those seeking asylum who are under 18, refused asylum seekers and those appealing their case. Glasgow is the only Scottish local authority participating in asylum dispersal, although other local authorities have accommodated asylum seekers separately through the Syrian Vulnerable Person Resettlement Scheme. 
social workers' perspectives and experiences of culturally competent social work practice (Harrison \& Turner, 2011; Willis, Pathak, Khambhaita, \& Evandrou, 2017). Although the scope of the study discussed in this paper was not limited to social workers' understandings of cultural competence with asylum seekers and refugees, the participants' reflections on power, positionality and participation largely focused on their experiences of working with these groups. As a result, this paper explores social workers' experiences of negotiating and accommodating cultural differences with service users who are simultaneously experiencing the compounding effects of displacement and immigration controls. The first part of this paper briefly reviews the key issues and concepts in the literature on social work and cultural diversity. The second part outlines social work with asylum seekers in the Scottish context. Following a description of the research methodology, this paper then goes onto analysing social workers' experiences of cross-cultural social work with asylum seekers.

\section{Cross-cultural social work}

Social work literature has become increasingly concerned with diversity, leading to the emergence of number of concepts addressing cross-cultural relations ${ }^{2}$. Cultural competence stands out from this literature, referring to a process by which professionals and organisations effectively and respectfully respond to the needs of their service users from diverse backgrounds (Danso, 2018). Although it has been argued that cultural competence has become widely recognised as a core ethical requirement for social

${ }^{2}$ As stated by Sheila Furness, the now common-place term 'cross-cultural competence' was coined to 'denote inclusive approaches in response to issues of diversity and difference in society' (Furness, 2005, p. 248). Although for the purposes of this article the treatment of the concept has been limited to social work with migrants, cross-cultural competence has become a concern in social work with range of groups with diverse needs. 
workers, no one is quite sure what cultural competence is or what it looks like (Harrison $\&$ Turner, 2011). Even though recent years have witnessed a rise in publications striving to 'revisit' and 'rethink' cultural competence for further clarity, much of this literature has only contributed to the growing number of new concepts on cross-cultural working, all of which arguably have more in common than what distinguishes them. The debate on cultural competence essentially comes down to three issues: (1) the tensions between essentialist and constructivist conceptualisations of culture; (2) the extent to which professionals can become 'competent' in the service user's culture (3) the emphasis on culture as an explanatory factor for service user's life circumstances and responses to social work. I will briefly revisit these issues, with a particular focus on the third issue which is the main concern of this paper.

Although culture has been subject to increasing attention both within and beyond social work, the concept remains complex, contested and vague (Park, 2005). The earliest, essentialist approaches to cross-cultural working framed culture as a static set of values, beliefs and practices, leading to a conceptualisation of competence as a process of obtaining relevant knowledge, skills and awareness (Nadan, 2017). Although influential, the essentialist and ethnocentric 'toolkit mentality' towards culture has been criticised for producing the other whose pre-determined culture can be known and thus, controlled (Abrams \& Moio, 2009, p. 254; Nadan, 2017). By othering, cultural difference becomes conceptualised as deficiency as minorities are stereotyped and constructed as being outside of the norm (Park, 2005). In contrast, advocates of constructivist conceptualisations of culture argue that recognising culture as a dynamic process 'liberates' the practitioner from the pursue to know the other (Ortega \& Faller, 2011, p. 34). Recognising the fluid nature of culture resists the tendencies to stereotype cultural minorities (Danso, 2018). Constructivist perspectives reconceptualise 
competency as practitioner's awareness of their own biases and cultural beliefs, as well as one's inherent limitations in understanding the service user's culture (Dean, 2001). However, not only what competency should encompass, but also what competency is remains unclear; it has been argued that the intangible and highly context-dependent nature of competency contradicts the over-reliance on standardisation of competencies in vocational training (Guthrie, 2009). This has also been said to be the case in social work; the 'theoretical stripping out' of frontline social work has left the profession vulnerable to "neo-liberal redefinition, exemplified in notions such as the focus on "competency"; a mentality which seeks to reduce "education" to "training", and critical practice to a set of procedural formulas', undermining the emancipatory potential of the profession (Singh \& Cowden, 2009, p. 487).

Although it has been argued that 'the introduction of cultural competence has brought more awareness to issues of diversity and difference in social work' (Danso, 2018, p. 412), it has paradoxically led to more narrow conceptualisations of difference. Cultural competence has been argued to conflate culture, ethnicity and race (Park, 2005), depoliticising issues arising from structural inequalities (Williams \& Parrott, 2013) and disregarding the socio-political mechanisms which produce ethno-racial injustices (Danso, 2018). Reducing social difference to culture has been argued to promote a colour-blind mentality which downplays the realities of institutional racism and structural inequalities (Abrams \& Moio, 2009; Thanki, 1994). Scholars have challenged the tendency to over-culturalise migrants' patterns of disadvantage, arguing for the need to incorporate other axis of social differentiation into the analysis of inequality (Boccagni, 2015; Jani, Pierce, Ortiz, \& Sowbei, 2011). As argued by Yochay Nadan, 'encounters between people who belong to different countries and continents are not merely cross-cultural, but often place them in positions of unequal power 
differentials' (2017, p. 74). There has been a growing emphasis to alternatives to cultural competence, including anti-racist (Abrams \& Moio, 2009) and anti-oppressive practice (Dominelli, 1996; Sakamoto \& Pitner, 2005). Most recently, concepts of intersectionality and superdiversity have emerged as promising tools for analysing inequality and difference. Superdiversity refers to the ways in which immigration has led to a transformative 'diversification of diversity' (Vertovec, 2007, p. 1025). Superdiversity as an analytical tool encourages us to move beyond ethnicity and culture to examining multiple factors underlying the service user's disadvantage (Boccagni, 2015). Those advocating for the merits of superdiversity perceive the concept to be more inclusive than intersectionality, although the latter has been increasingly applied beyond its initial focus on the triad of race, gender and class (Crenshaw, 1991). In focusing on multiple positionalities, intersectionality has been argued to support the analysis of how culture influences and is influenced by individual characteristics and societal factors (Nadan, Spilsbury, \& Korbin, 2015). Although both concepts have been argued to support practitioners in developing structural and multidimensional understandings of the service users' disadvantage (Boccagni, 2015; Hendriks \& van Ewijk, 2019; Jani et al., 2011), it is still unclear how these should best be operationalised in everyday encounters with service users from diverse backgrounds. Regardless of the critique, culture continues to play part in the social work encounters; culture influences sense of identity, child-rearing practices and understandings of harm (Dalikeni, 2019; Korbin, 1991). Further, both professional and personal cultures influence social workers' responses to child protection concerns (Dalikeni, 2019). It has been argued that a lack of cultural understanding often results in social work operating against the interests of BME service users (Graham, 2002). Cross-cultural working challenges social workers to find a balance between 
ethnocentrism that reinforces unequal power relationships, and extreme relativism that can lead to failures to protect service users from harm (Korbin, 1991). Although crosscultural social work has been increasingly theorised, the empirical research into social workers' attempts to translate cultural competence into practice remains limited. Further, much of the discussion on social work with asylum seekers has focused on resettlement and mental health work, and only recently have researchers begun interrogating cross-cultural issues in the context of displacement (Dalikeni, 2019). Thus, this paper addresses this gap by analysing social workers' understandings and experiences of culturally competent practice with asylum seekers.

\section{Social work with asylum seekers in Scotland}

In Scotland, majority of the social workers are employed by local authorities and all social work with asylum seekers falls under public provision. Asylum seekers and refugees are entitled to access social care provision under the Section 12 of the Social Work (Scotland) Act 1968 (Scottish Refugee Council, 2019). However, asylum seekers are not entitled to access general social work services when such need arises from destitution or the physical effects of their destitution (Scottish Refugee Council, 2019). The statutory social work involvement with asylum seekers in Scotland is limited; unlike the Nordic countries, the UK does not have reception centres where social workers are involved in the reception and integration work. Social workers also do not undertake asylum seeker welfare assessments like they do in countries like Cyprus (Cochliou \& Spaneas, 2009). Instead, asylum support is standardised and includes a $£ 37.75$ weekly allowance and basic dispersal housing. Asylum seeking children regarded as children in need under Children (Scotland) Act 1995 (Scottish Refugee Council, 2019). The local authorities have a duty to safeguard and promote the welfare 
of all children in need through provision of services and assistance that considers the child's cultural background.

In the cases discussed in this paper, immigration and displacement were not the primary reasons for social work involvement. The interviewed social workers had worked with displaced families due to child protection concerns, and social workers in criminal justice teams had engaged with refused asylum seekers as a condition of their parole which they were under due to non-immigration related offences. In discussing these cases, this article demonstrates how displacement and immigration controls increasingly play part in social work, particularly in cases where cross-cultural conflicts are concerned. With increased number of displaced people in Europe, issues concerning asylum are no longer only a concern of specialist service provision in reception centres, but increasingly of everyday social work.

\section{Methodology}

The following discussion draws from qualitative findings that form a part of a mixed methods study carried out in Glasgow, Scotland in 2016. The overall study explored social workers' experiences of translating cultural competence into everyday practice. The quantitative component, which is beyond the scope of this paper, employed a questionnaire to assess social workers' self-assessed professional capacity, confidence as well as available training and support for working with diverse service users. The qualitative findings are based on semi-structured interviews with eight social work managers and frontline staff working in different children and families $(n=5)$, youth justice $(n=1)$ and criminal justice teams $(n=2)$, with work experience ranging from two to over twenty years. Heterogenous purposive sampling strategy was used to recruit 
participants with diverse work histories for the purposes of examining cultural competence in the context of the changing society and social work practice.

The individual interviews explored the meanings social workers inscribe on cultural competence and their experiences of translating these meanings into practice. The second part of the interviews invited the participants to respond to three open-ended narrative vignette scenarios depicting cross-cultural conflicts. In contrast to previous research that has employed two versions of the same vignette to explore social workers' responses to ethnicity (Williams \& Soydan, 2005), the same vignettes were shared with all participants for the purposes of exploring how social workers would approach complex cultural issues and what resources they would draw upon in doing so. The two scenarios which are relevant to social work with asylum seekers described the potential risks of Female Genital Mutilation/Cutting (FGM/C) and forced marriage, issues which in the UK have sparked growing public pressure towards service providers to further safeguard vulnerable children and adults. FGM/C in particular was selected due to the challenges these practices pose to social workers in assessing risk, identifying victims and in engaging with potentially affected communities in a culturally sensitive manner. FGM/C is a prime example of practices which, depending on the cultural context, can be understood as being done in the worst or the best intentions for the child, underlining the need for professionals to reflect differing cultural constructions of harm (Korbin, 1991). The vignettes prompted the participants to discuss their previous experiences of addressing these issues, to reflect upon their personal and professional values and to discuss the barriers they experienced in working with service users from diverse backgrounds.

Before data collection, the research was granted ethical approval by the School Ethics Committee. All participants gave their informed written consent to be 
interviewed and the anonymised data to be used in written publications. Following data collection and verbatim transcription, the interview and vignette data was thematically analysed by using inductive codes. The codes were then sorted into set of themes which were reviewed and refined following the approach outlined by Braun and Clarke (2006). Thematic analysis of the data was considered well-suited for its' ability to capture subtle nuances and latent meaning in the participants' narratives.

The small sample size and the study location in a dispersal city mean that similar findings may not emerge in other research settings. Although the small sample size is a limitation for the purposes of developing a more comprehensive understanding of practitioners' experiences, the in-depth interviews nevertheless provided rich perspectives which further our understanding of the ways global issues can shape localised social work encounters. Although the findings specifically relate to the Scottish context, the impacts of increasing migration and associated fortress mentality highlighted in the following sections may also be of concern in other European contexts ${ }^{3}$. This provides a direction for further research to explore how issues related to displacement, immigration controls and migrant resettlement influence cross-cultural practice in other areas.

\footnotetext{
${ }^{3}$ It has been argued that 'the increasing perception of (uncontrolled) immigration as potential security threat has led to a migration approach that is mainly based on defence and deterrence' in the EU (Völkel, 2014, p. 151). This can be seen in the tighter immigration controls and growing public pressure to reduce the number of asylum seekers across Europe. In the UK, the Home Office hostile environment policy targets immigrants with no right to remain with a range of measures restricting their employment, housing and access to welfare services.
} 


\section{Findings}

The following discussion presents the integrated findings from the interviews and vignette discussions. The first part focuses on social workers' constructions of cultural competence and culture in social work with asylum seekers. The second part analyses social workers' examples of good practice with asylum seekers. Although cultural competence is used as an umbrella term for the purposes of consistency, the participants convey an understanding of competence which moves beyond cultural knowledge and awareness. When it comes to constructions of difference and disadvantage, the findings illustrate a demand for practitioners to address the ongoing interplay of cultural and structural explanations of service users' situations.

\section{Social workers' constructions of cultural competence}

Although the participants conveyed somewhat different understandings of cultural competence, all social workers considered cultural knowledge relevant for working with migrants:

I: What does cultural competence mean to you?

SW5: I think for me it is to be aware of the cultural identity, traditions and norms of that person you are working with... taking that into account and see how I can do my job without breaking down or breaking over any of those traditions and stuff. So, what I mean in a sense it is more to do with respecting the person, respecting the culture while still having a job to do in terms of social work.

Social workers said that cultural knowledge supported them in signifying respect towards service users by enabling them to accommodate religious and cultural customs around food, family life and celebrations. On the other hand, cultural knowledge was 
also seen useful for mitigating risks; for instance, one of the participants described how a service user's family had initially told her their daughter could marry whoever she wanted, but that only with further prompting she uncovered this was restricted to Muslims, excluding the Ahmadiyya community. Lastly, social workers believed knowledge was important for avoiding 'racism by omission'. Whilst the participants considered that working with both majority and minority service users necessitated addressing 'similar themes of poverty, isolation and poor mental health', social workers were mindful of how institutional racism contributed to BME service users' situations (Abrams \& Moio, 2009). In emphasising culture as something which the service users had and which the social workers could understand, participants conveyed an essentialist view of culture (Park, 2005). However, the participants also described a more constructivist understanding in critically reflecting their own 'ignorance', 'naivety' and 'feeling of incompetence' in relation to different cultures. Social workers resisted framing migrants as cultural others, criticising constructing service users' cultures in inferior terms (Park, 2005):

I think as social workers we must be culturally aware that what I believe is right is not necessarily what somebody from Africa believes is right. And who's to say my values or beliefs are kind of superior, or better than somebody else's? [Social worker 2]

Social workers also critically reflected the place of problematic behaviours in their own cultures; for instance, in discussing the normative place corporeal punishment had as part of Scottish parenting until the very recent times. In discussing cross-cultural conflicts, some participants also brought up the challenges they faced in dealing with 
local cultural issues around domestic abuse, football violence and sectarian rivalries ${ }^{4}$

All participants discussed the importance of actively exploring service users' subjective meanings of culture and their sense of belonging. This was about developing an understanding of how 'the service user's representation of their culture may differ from my perception of their culture'. The influence of migration was a key consideration for social workers. Participants advocated for the need to interrogate service users' cultural identities in light of migrants' ongoing negotiation between past and present; for instance, when assessing a risk of forced marriage in the second vignette, this required exploring whether the service user perceived himself 'first as Scottish, and Indian second'. In assessing service users' situations, developing an understanding of service users' routes became just as pertinent as their roots:

Because the population we come across aren't here necessarily by desire, so before we even encounter any sort of cultural exchange, we need to understand their journey, what it looked like, what it felt like. [Service Manager]

Culture can act as a continuity in the face of multiple discontinuities, giving structure, security and meaning in new contexts (Valtonen, 2002). This underscores the need for self-reflexivity whereby, 'social worker comes to a realisation that some of the behaviour she has seen as problematic on the part of her clients may in fact be resistance' (Heron, 2005, p. 348). Social workers argued for the need to develop an understanding of what the service user 'believed what was happening to them' in order to 'see them for what had happened to them'. Rather than addressing cultural practices in

4 Although beyond the scope of this article, the relationship between religion, football and identity is one which strongly characterises the social and cultural landscape in the west of Scotland. 
isolation, the participants located the continuation of cultural practices in the context of migrants' past life and experiences of loss:

Obviously they have to live by our countries' laws, but it can be very difficult for families that we are basically saying, no, you've got to forget what you did in your country, this is how we do things here and you have to do things our way now... ....and all of a sudden everything has got to change. [Social worker 2]

Although social workers emphasised the need to build a deeper understanding of the service users' situations, the realities of the job were often limiting their abilities to do so. Funding cuts, increased workloads and public exposure were said to have transformed social work into an 'emergency service'. Participants suggested this had led to a tendency within social work to 'catastrophise situations' at the expense of taking the time to 'see the bigger picture'. Nevertheless, the participants cautioned against 'hands-on' practice with ethnic minorities in which social workers' biased assumptions could lead to disproportionate interventions (Dominelli, 1998). Especially when addressing concerns around cultural practices which have been the subject of increased public attention, reflexivity required social workers to question the ways dominant discourses could pertain to social work safeguarding practices:

[In discussing the vignette about the risk of FGM/C] Part of what we have to do is bring people back to reality - let's not get tied up thinking that every child that goes abroad is going to be mutilated. [Service Manager] 


\section{Locating structural issues in cultural conflicts}

It has been argued that over-reliance on cultural explanations can detract from the structural factors influencing the service users' situations (Ahmed, 1994). In discussing harmful cultural practices, participants argued that focusing solely on the service user's culture was not enough to address the inequalities which gave rise to social work involvement in the first place. Social workers suggested that the lack of measures to actively inform new arrivals of their rights and responsibilities in Scotland had been instrumental in contributing to the continuation of behaviours which had previously been socially sanctioned in the service users' countries of origin:

\footnotetext{
A woman had hit her son with I think a cable or something, and what she said to me was that it would help the people coming into the country if they were given information about the laws and what the laws here were in relation to their children, and then they would have an idea of what was expected of them. She felt they were stigmatised against because they were coming from a different country and they didn't know, and they weren't given the information. [Social worker 3]
}

Social workers emphasised their need to remain vigilant about the ways their service users' access to knowledge and as a result, to meaningful participation, was obstructed by the asylum system and resettlement difficulties. This illustrates the value of including factors such as legal and resettlement status in the social work assessment to develop a more nuanced understanding of the service user's disadvantage (Boccagni, 2015).

Participants also discussed their need to recognise how wider inequalities influenced the service users' reactions to social work intervention. When working with service users who were fleeing state persecution and now experienced institutionalised 
hostility upon relocation, service users' responses demanded the practitioners to interrogate how service users' experiences of authority before and after coming to the UK had contributed to their negative perceptions of the social work services. Participants said that service users' assumptions about the connections between social work, police and the Home Office often manifested their past experiences of state violence or their current fears of deportation, leading to a very different interpretation of the professional skills social workers employed in cross-cultural encounters:

The mother was like 'Why are you here? Why are you asking all these questions? Why do you want to know about me and my children and our past?'. Because I've been asking them why they came over from Africa here, what life is like in Africa, what experiences they have had, so I can get a better picture of the lives of the children. Whereas the mother thinks I am snooping, and that I am looking for reasons to send them back to their own culture and that I am going to feed this back to the border agency and authorities. [Social worker 3]

All but one of the interviewed social workers discussed cases where their intervention has been viewed with suspicion or was perceived as racist:

I find it difficult to be called racist which I get called often... but I suppose I need to move beyond that and understand why they would view social work as racist. They don't have a social work department where they are coming from, so all of a sudden these white people rock up and say you can't be doing that and they say "you're being racist because this is the way we've always done it" and the church says it's okay and family says it's okay and this is the way they were brought up. [Team leader] 
Racial tensions were also present in working with asylum seekers with differentiated access to welfare:

I've worked with a family from Nigeria, they had come to our attention because mum had mental health problems and the family had been refused leave to remain here. Their money was cut off, they had nothing, they were living on nothing. What they felt was happening to them was the interesting part because they felt as they were treated differently because of their race, but it wasn't that it was the system, they were refused asylum. [Social worker 4]

Within the current context of international displacement, asylum restrictions largely affect BME migrants who are already disproportionately represented in social welfare statistics (Graham, 2002). Social workers criticised the way the asylum system marginalised service users through forced unemployment, dispersal housing and differential access to social security. One of the participants argued that asylum seekers were 'moved like cattle', as the Home Office was seen to intentionally complicate their lives in so far as to make them withdraw their applications. He described how asylum seekers had been made to live in shared accommodation where they had been targeted for their appearance and forced to pay travel across the city from their limited funds to report weekly to the Home Office, despite living across the road from a police station. Although the participant had tried to mitigate the impacts of these hostile measures by arranging their supervision at the same time so he could drive the service user to the border agency, he felt there was little he could do at the end of the service user's license period. Recent research has been critical of framing cultural competence solely as a responsibility of an individual practitioner, highlighting the role of the organisational context in the provision of culturally appropriate services (Harrison \& Turner, 2011). In 
addition to recognising their own unpreparedness to deal with asylum issues, the participants largely felt that the profession was ill-equipped for addressing the "multilayered problems and trauma' faced by asylum seekers and refugees. Participants said that there was a lack of clear guidance within the organisation on how best to support service users with no recourse to public funds, which limited social workers' ability to support asylum seekers' access to rights and resources.

\section{Translating perspectives into practice: from conflicts to collaboration}

It has been argued that meaningful partnerships can address the disproportionate representation of black people in social welfare statistics (Graham, 2002). In discussing service users' negative perceptions of social work intervention, the participants emphasised the importance of partnership working in order to 'help families to help themselves'. The participants felt that engaging with communities, religious leaders and families was paramount to addressing cross-cultural conflicts. For instance, three of the participants had begun reaching out to African community churches to address community attitudes toward physical chastisement and social work intervention. Nevertheless, the participants remarked how the profession had increasingly moved away from preventative community work and was now more limited to responding to child protection concerns, which restricted their abilities to build ties with communities.

Advocates of anti-oppressive social work have called for integrating different ways of knowing into predominantly White and Western social work practice (Sakamoto, 2007). Instead of approaching cross-cultural conflicts in a manner which service users would perceive as imposing Western values onto them, social workers attempted to locate the same values in the service users' cultures. For example, rather than conveying the rejection of corporal punishment as a Western cultural norm, a social 
worker had encouraged a Chinese couple to explore publications from Chinese Universities which would challenge their beliefs. Two of the participants also shared their successes in informing service users about the societal expectations by using a parenting manual resource developed by an African-led charity organisation. This resource supported the social workers to simultaneously address harmful cultural behaviours, service users' barriers to accessing information as well as their perceptions of social work as racist. By basing their work on community-based knowledge, social workers were successful in advocating positive parenting whilst engaging themselves in learning about differing cultural perceptions and challenges faced by new arrivals. As outlined by one of the participants, drawing from community-based knowledge was a key in safeguarding children in a way in which 'acknowledged the mum's background, mum's own experiences and mum's own perceptions of what it looks like to be a good mum'. This illustrates collaborative practice whereby social workers move beyond evidence and expertise which resides within the Western and professional paradigms to address cultural and racial tensions.

\section{Connecting social justice with culture}

Working with asylum seekers not only required the participants to consider how multiple disadvantages influenced cultural issues, but conversely, to also incorporate cultural considerations into efforts to mitigate structural inequalities. Although there has been little to show that social workers can work against the system/s in which they operate (Millar, 2008), the participants still emphasised the need to address the disadvantages that asylum seekers were experiencing. The lack of organisational focus on addressing asylum seekers' situations led some social workers to proactively look beyond formal welfare provision which excluded their service users. One of the 
participants had signposted destitute service users to a local charity-run foodbank which prepared halal food parcels. Although a small gesture, this offered the social worker some limited scope to mitigate the effects of discriminatory policies the service users were facing, whilst simultaneously accommodating their cultural beliefs. Refusal of public funds had led a Somalian asylum seeker to become totally reliant on his sister, which in turn had provoked feelings of shame as he was unable to meet the cultural expectations he was accustomed to. Although he initially hesitated, the social worker encouraged him to rethink accessing the foodbank as an alternative means to put food on the table, which in his culture was traditionally seen as the responsibility of the man. By arranging a three-way meeting, the social worker was able to ensure that receiving food parcels would not provoke further feelings of shame as although his sister was fully aware of where the food was coming from, 'she knows what it cost him'.

This example highlights how, especially when working with asylum seekers who experience constraints to exercise power at multiple levels, social workers need to operate in ways that do not contribute to service users' sense of powerlessness. Although accessing a foodbank hardly dismantles the institutionalised inequalities which have been sanctioned by the prevailing hostile attitudes to immigration, this example nevertheless demonstrates social work practice from an anti-oppressive standpoint through 'linking issues of social justice with culture' (Parrott, 2009, p. 617). This illustrates cross-cultural working that not only accommodates diversity within the care relationship, but which further facilitates the service users' right to their cultural selves in the wider society. However, in the face of asylum seekers' multidimensional and institutionalised disadvantage, many of the participants raised concerns of their limited abilities to improve the service users' situations through conventional welfare mechanisms. 


\section{Concluding remarks}

This paper has illustrated the interplay between cultural and structural considerations involved in social work with asylum seekers. On one hand, addressing cultural issues requires social workers to consider how structural inequalities shape service users' perceptions of, and responses to social work involvement. On the other, social workers' perspectives suggest that practice which promotes social justice should also incorporate cultural considerations to counter asylum seekers' sense of powerlessness.

Cultural knowledge and awareness continue retain some significance to practice, especially in supporting social workers in accommodating cultural differences and understanding religious nuances. However, practitioners' focus on exploring how service users' culture and circumstances are affected by migration, loss and power relationships suggest moving beyond the cultural lens in analysing difference and disadvantage. In the context of increasing migration and tighter immigration controls, culture is no longer the only form of difference which social workers are confronted by. The differentiated 'welfare' system and internal and external forms of control asylum seekers are subject to have become a concern in every day social work practice. The findings suggest that cross-cultural conflicts cannot be adequately addressed without considering how experiences of wider oppression play out in the caring relationship.

The participants' perspectives suggest that with increasing migration, "the task of linking the global and local becomes a part of the practice of every social worker" (Ife, 2001, pp. 4). Recognising how the continuation of cultural practices and service users' negative responses to social work intervention are influenced by migrants' past and present experiences of marginalisation brings considerations around the relationship between power and knowledge production to the fore of cross-cultural working. Whilst knowledge is a central component of social work, so should be the ongoing attempt to 
question the knowledge and terms by which it is produced to avoid re-inscribing domination within the care relationship (Sakamoto \& Pitner, 2005). As cultural and racial tensions manifest themselves in particular ways in different contexts, further research is needed to understand social workers' experiences of the challenges and successes in cross-cultural practice with displaced migrants. Further, as already highlighted by others (Boccagni, 2015), there is a need to develop an understanding of service users' conceptualisations and experiences of good practice. Understanding refugees' perspectives may support social workers to further incorporate communitybased knowledges and partnership working in everyday practice with migrant service users.

Recognising the organisational limitations in the provision of culturally sensitive services raises the question to what extent individual social workers can effectively address the wider structures that sustain oppression. Doing so would require new competencies from the wider social work organisation to support practitioners' in addressing state-sanctioned inequalities. The constraints faced by social workers discussed here are not unique to Scotland; globally, social workers are increasingly operating in a landscape characterised by both internal and external pressures arising from austerity and the neoliberal re-constructing of welfare provision (Ioakimidis, Santos, \& Martinez Herrero, 2014; Spolander et al., 2014). Although social workers' examples of good practice reflect the anti-oppressive principles of partnership, empowerment and reflexivity, further research is needed to understand how social workers can work towards social justice within the increasingly constrained parameters of the profession. 


\section{Acknowledgments}

The author would like to thank the guest editor and both anonymous reviewers for their helpful feedback for improving this paper.

\section{Disclosure of interest}

The author reports no conflict of interest.

\section{Funding}

This research was supported by ESRC Social Work Pathway 1+3 Doctoral Training Grant.

Word count: 6998

\section{References}

Abrams, L. S., \& Moio, J. A. (2009). Critical race theory and the cultural competence dilemma in social work education. Journal of Social Work Education, 45(2), 245261. https://doi.org/10.5175/JSWE.2009.200700109

Ahmed, S. (1994). Anti-racist social work: a black perspective. In C. Hanvey \& T. Philpot (Eds.), Practising Social Work. London: Routledge.

Boccagni, P. (2015). (Super)diversity and the migration-social work nexus: a new lens on the field of access and inclusion? Ethnic and Racial Studies, 38(4), 608-620. https://doi.org/10.1080/01419870.2015.980291

Braun, V., \& Clarke, V. (2006). Using thematic analysis in psychology. Qualitative Research in Psychology, 3(2), 77-101. 
https://doi.org/10.1191/1478088706qp063oa

Cochliou, D., \& Spaneas, S. (2009). Asylum system in Cyprus: a field for social work practice. European Journal of Social Work, 12(4), 535-540.

https://doi.org/10.1080/13691450903323024

Crenshaw, K. W. (1991). Mapping the Margins: Identity Politics, Intersectionality, and Violence against Women. Standford Law Review, 43(6), 1241-1299.

https://doi.org/10.2307/1229039

Dalikeni, C. (2019). Child-rearing practices: cross cultural perspectives of African asylum-seeking families and child protection social workers in Ireland. European Journal of Social Work, 1-13. https://doi.org/10.1080/13691457.2019.1585333

Danso, R. (2018). Cultural competence and cultural humility: A critical reflection on key cultural diversity concepts. Journal of Social Work, 18(4), 410-430. https://doi.org/10.1177/1468017316654341

Dean, R. G. (2001). The myth of cross-cultural competence. Families in Society: The Journal of Contemporary Social Services, 82(6), 623-630. https://doi.org/https://doi.org/10.1606\%2F1044-3894.151

Dominelli, L. (1996). Deprofessionalizing social work: anti-oppressive practice, competencies and postmodernism. The British Journal of Social Work, 26(2), 153175. https://doi.org/10.1093/oxfordjournals.bjsw.a011077

Dominelli, L. (1998). Multiculturalism, anti-racism and social-work in Europe. In H. Soydan \& M. Johnson (Eds.), Social Work and Minorities. London: Routledge. Furness, S. (2005). Shifting sands: Developing cultural competence. Practice, 17(4), 247-256. https://doi.org/10.1080/09503150500425638

Graham, M. (2002). Creating Spaces: Exploring the Role of Cultural Knowledge as a Source of Empowerment in Models of Social Welfare in Black Communities. 
British Journal of Social Work, 32, 35-49.

Guthrie, H. (2009). Competence and competency-based training: What the literature says. 1-32. https://doi.org/ISBN 9781921413

Harrison, G., \& Turner, R. (2011). Being a “culturally competent” social worker: making sense of a murky concept in practice. The British Journal of Social Work, 41(2), 333-350. https://doi.org/10.1093/bjsw/bcq101

Hendriks, P., \& van Ewijk, H. (2019). Finding common ground: how superdiversity is unsettling social work education. European Journal of Social Work, 22(1), 158170. https://doi.org/10.1080/13691457.2017.1366431

Heron, B. (2005). Self-reflection in critical social work practice: subjectivity and the possibilities of resistance. Reflective Practice, 6(3), 341-351.

https://doi.org/10.1080/14623940500220095

Home Office. (2017). Immigration Statistics: Asylum data tables October to December 2017, volume 4. Retrieved from https://www.gov.uk/government/uploads/system/uploads/attachment_data/file/691 967/asylum4-oct-dec-2017-tables.ods

Ife, J. (2001). Local and global practice: Relocating social work as a human rights profession in the new global order. European Journal of Social Work, 4(1), 5-15. https://doi.org/https://doi.org/10.1080/714052835

Ioakimidis, V., Santos, C. C., \& Martinez Herrero, I. (2014). Reconceptualizing social work in times of crisis: An examination of the cases of Greece, Spain and Portugal. International Social Work, 57(4), 285-300. https://doi.org/10.1177/0020872814524967

Jani, J. S., Pierce, D., Ortiz, L., \& Sowbei, L. (2011). Access to intersectionality, content to competence: Deconstructing social work education diversity standards. 
Journal of Social Work Education, 47(2), 283-301.

https://doi.org/10.5175/JSWE.2011.200900118

Korbin, J. E. (1991). Cross-cultural perspectives and research directions for the 21st century. Child Abuse and Neglect, 15(SUPPL. 1), 67-77.

https://doi.org/10.1016/0145-2134(91)90010-B

Millar, M. (2008). “Anti-Oppressiveness": Critical comments on a discourse and its context. The British Journal of Social Work, 38(2), 362-375. https://doi.org/10.1093/bjsw/bcl336

Nadan, Y. (2017). Rethinking 'cultural competence' in international social work. International Social Work, 60(1), 74-83. https://doi.org/10.1177/0020872814539986

Nadan, Y., Spilsbury, J. C., \& Korbin, J. E. (2015). Culture and context in understanding child maltreatment: Contributions of intersectionality and neighborhood-based research. Child Abuse and Neglect, 41, 40-48. https://doi.org/10.1016/j.chiabu.2014.10.021

Nylund, D. (2006). Critical multiculturalism, whiteness, and social work: Towards a more radical view of cultural competence. Journal of Progessive Human Services, 17(2), 27-42. https://doi.org/10.1300/J059v17n02_03

Ortega, R. M., \& Faller, K. C. (2011). Training child welfare workers from an intersectional cultural humility perspective: A paradigm shift. Child Welfare, 90(5), 27-50. Retrieved from https://s3.amazonaws.com/academia.edu.documents/42592172/Ortega_Faller_Chil d_Welfare_-_CH_Training_in_CW.pdf?response-content-disposition=inline\%3B filename\%3DCultural_Humility_for_Child_Welfare_Prof.pdf\&X-AmzAlgorithm=AWS4-HMAC-SHA256\&X-Amz-Credential=A 
Park, Y. (2005). Culture as deficit: A critical discourse analysis of the concept of culture in contemporary social work discourse. Journal of Sociology and Social Welfare, 32(3), 11-33. Retrieved from https://heinonline.org/HOL/LandingPage?handle=hein.journals/jrlsasw32\&div=32 \&id $=\&$ page $=$

Parrott, L. (2009). Constructive marginality: Conflicts and dilemmas in cultural competence and anti-oppressive practice. Social Work Education, 28(6), 617-630. https://doi.org/10.1080/02615470903027322

Sakamoto, I. (2007). An anti-oppressive approach to cultural competence. Canadian Social Work Review, 24(1), 105-114. Retrieved from https://www.jstor.org/stable/41669865?seq=1\#page_scan_tab_contents

Sakamoto, I., \& Pitner, R. O. (2005). Use of critical consciousness in anti-oppressive social work practice: Disentangling power dynamics at personal and structural levels. The British Journal of Social Work, 35(4), 435-452. https://doi.org/10.1093/bjsw/bch190

Scottish Refugee Council. (2019). Factsheet: Health. Retrieved from www.scottishrefugeecouncil.org.uk/what_we_do/

Simpson, L. (2014). How has ethnic diversity changed in Scotland? Dynamics of Diversity Series. In Dynamics of diversity: evidence from the 2011 census. Retrieved from http://hummedia.manchester.ac.uk/institutes/code/briefings/dynamicsofdiversity/co de-census-briefing-scotland_v2.pdf

Singh, G., \& Cowden, S. (2009). The social worker as intellectual. European Journal of Social Work, 12(4), 479-493. https://doi.org/10.1080/13691450902840689

Spolander, G., Engelbrecht, L., Martin, L., Strydom, M., Pervova, I., Marjanen, P., ... 
Adaikalam, F. (2014). The implications of neoliberalism for social work:

Reflections from a six-country international research collaboration. International Social Work, 57(4), 301-312. https://doi.org/10.1177/0020872814524964

Thanki, V. (1994). Ethnic Diversity and Child Protection. Children \& Society, 8(3), 232-244. https://doi.org/10.1111/j.1099-0860.1994.tb00427.x

Valtonen, K. (2002). Social Work with immigrants and refugees: Developing a participation-based framework for anti-oppressive practice, Part 2. The British Journal of Social Work, 32(1), 113-120.

https://doi.org/https://doi.org/10.1093/bjsw/32.1.113

Vertovec, S. (2007). Super-diversity and its implications. Ethic and Racial Studies, 30(6), 1024-1054. https://doi.org/10.1080/01419870701599465

Völkel, J. C. (2014). Money for Nothing, the Cricks for Free: Five Paradoxes in EU Migration Policy. Comparative Migration Studies, 2(2), 151-180. Retrieved from https://link.springer.com/article/10.5117/CMS2014.2.VOLK

Williams, C., \& Parrott, L. (2013). From specialism to genericism: Rising and falling to the challenges of responding to racial and ethnic diversity in social work education in Wales. British Journal of Social Work, 43(6), 1206-1224. https://doi.org/10.1093/bjsw/bcs042

Williams, C., \& Soydan, H. (2005). When and how does ethnicity matter? A crossnational study of social work responses to ethnicity in child protection cases. British Journal of Social Work, 35(6), 901-920. https://doi.org/10.1093/bjsw/bch281

Willis, R., Pathak, P., Khambhaita, P., \& Evandrou, M. (2017). Complexities of cultural difference in social care work in England. European Journal of Social Work, 20(5), 685-696. https://doi.org/10.1080/13691457.2016.1255597 
